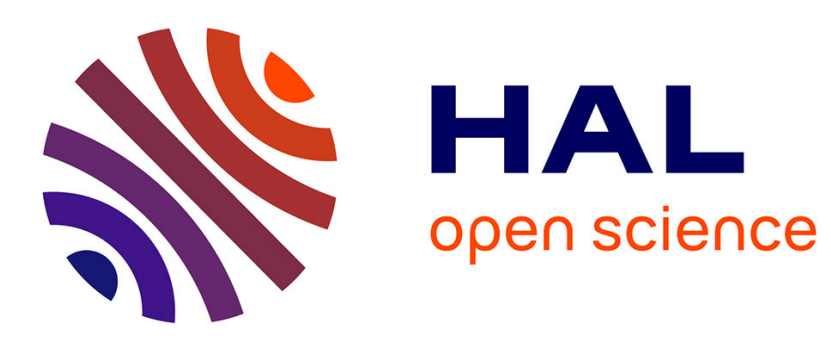

\title{
On the analysis of the beam energy stabilization in the Van de Graaff accelerator " Lech"
}

\author{
A. Bieńkowski, M. Jaskóla, L. Zemlo
}

\section{To cite this version:}

A. Bieńkowski, M. Jaskóla, L. Zemlo. On the analysis of the beam energy stabilization in the Van de Graaff accelerator " Lech ". Revue de Physique Appliquée, 1977, 12 (10), pp.1323-1325. 10.1051/rphysap:0197700120100132300 . jpa-00244316

\section{HAL Id: jpa-00244316 https://hal.science/jpa-00244316}

Submitted on 1 Jan 1977

HAL is a multi-disciplinary open access archive for the deposit and dissemination of scientific research documents, whether they are published or not. The documents may come from teaching and research institutions in France or abroad, or from public or private research centers.
L'archive ouverte pluridisciplinaire HAL, est destinée au dépôt et à la diffusion de documents scientifiques de niveau recherche, publiés ou non, émanant des établissements d'enseignement et de recherche français ou étrangers, des laboratoires publics ou privés. 


\title{
ON THE ANALYSIS OF THE BEAM ENERGY STABILIZATION IN THE VAN DE GRAAFF ACCELERATOR « LECH »
}

\author{
A. BIEŃKOWSKI $\left({ }^{*}\right)$, M. JASKÓŁA $\left({ }^{* *}\right)$ and L. ZEMŁO $\left({ }^{* *}\right)$
}

\begin{abstract}
Résumé. - La fluctuation d'énergie du faisceau de l'accélérateur Van de Graaff $L E C H$ est détectée par un système d'analyse standard consistant en un aimant de $90^{\circ}$ suivi d'une paire de fentes. Le signal d'erreur venant des fentes est utilisé pour corriger la haute tension au terminal. La correction des composantes rapides est faite par l'intermédiaire de la triode - corona tandis que pour les composantes lentes on ajuste le courant de charge sur la courroie. En vue de déterminer le gain maximum compatible avec une opération stable nous avons adopté une fonction de transfert bien définie pour stabiliser les 2 boucles mentionnées ci-dessus. Ensuite nous avons appliqué cette fonction à l'analyse de la stabilité du système de courte réaction. Bien que le calcul ait été fait avec les paramètres de l'accélérateur $L E C H$, la même méthode est facilement applicable à d'autres accélérateurs Van de Graaff.
\end{abstract}

Abstract. - In the Van de Graaff accelerator $L E C H$ the deviation of the beam energy from the desired value is detected by the standard analysing system consisting of the $90^{\circ}$ bending magnet followed by a pair of slits. The amplified error signal from that slits is used to correct the high voltage at the terminal. Corrections of the fast component of the voltage instability are made via the corona-triode and for the slow component via adjustment of the belt charging current.

In order to determine the maximum gain factors providing the stable operating conditions we have adopted a definite transfer function for the aforementioned two loop stabilizer. Next we have applied this function to the analysis of the stability of the feedback system. Although the calculation was made for parameters of the accelerator $L E C H$, the same method is easily applicable to other Van de Graaff accelerators.

In the Van de Graaff accelerator Lech the deviation of the beam energy from the desired value is detected by the standard analysing system consisting of the $90^{\circ}$ bending magnet followed by a pair of slits. The amplified error signal from those slits is used to correct the high voltage at the terminal. Corrections of the fast component of the voltage instability are made via the corona-triode and for slow component via adjustment of the belt charging current. Figure 1 shows the schematic diagram of our accelerator.

The block diagram of the regulating system is shown in figure 2. $E_{\mathrm{s}}$ represents the steering signal determined by the magnitude of the magnetic field in the analysing magnet. The signal $E_{\mathrm{i}}$ represent the energy of the ions at the exit of the accelerator tube. The error signal $\Delta E=E_{\mathrm{s}}-E_{\mathrm{i}}$ in the form of the difference of currents from the exit slits is amplified by the amplifier A.

The accelerator considered as an integrating circuit has the time constant:

$$
T_{\mathrm{e}}=C_{\mathrm{k}} \cdot R
$$

where:

$C_{\mathrm{k}}-$ the terminal to ground capacity

(*) Institute of Experimental Physics, Warsaw University, Poland.

(**) Institute of Nuclear Research. Warsaw, Poland.

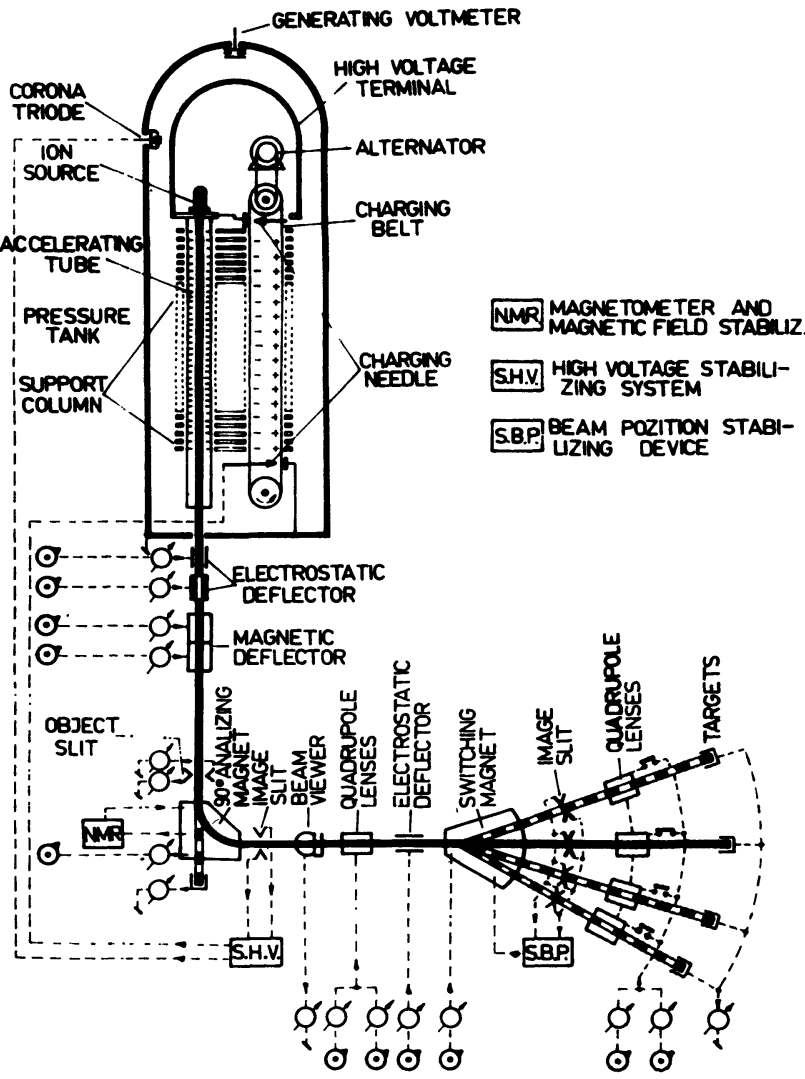

FIG. 1. - Schematic diagram of the accelerator $L E C H$. 


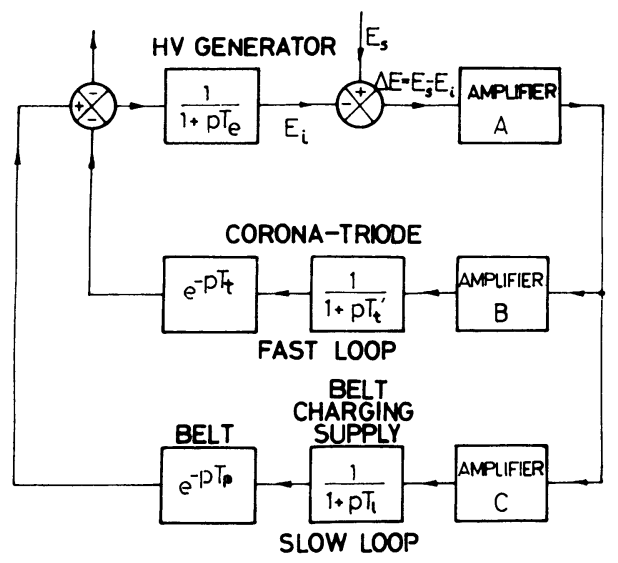

FIG. 2. - Block diagram of regulating system.

$R$ is estimated by the formula:

$$
\frac{1}{R}=\frac{1}{R_{\mathrm{d}}}+\frac{I}{U}
$$

where:

$R_{\mathrm{d}}$ - the divider resistance

$I$ - the load current (the beam current, the leakage current, etc.)

$U$ - the terminal voltage.

$R$ min. $=4.5 \times 10^{9} \Omega$ From that $T_{\mathrm{e}} \min .=0.67 \mathrm{~s}$ $R \max .=42.3 \times 10^{9} \Omega$ From that $T_{\mathrm{e}} \max .=6.35 \mathrm{~s}$

The response of the terminal to the corona-triode is described by two time constants: $T_{\mathrm{t}}$ and $T_{\mathrm{t}}^{\prime}$. The time delay $T_{\mathrm{t}}$ is the minimum ion transit time from the corona points to the terminal, $T_{\mathrm{t}}^{\prime}$ is the spread of the transit time. If the voltage of the needles of the corona-triode is rapidly changed, the terminal potential starts to change exponentially with the time constant $T_{\mathrm{t}}^{\prime}$ after the delay-time $T_{\mathrm{t}}$. The above time constants have been measured. At $3 \mathrm{MV}$ terminal voltage and at $10 \mathrm{~atm}$ gas pressure $T_{\mathrm{t}}$ and $T_{\mathrm{t}}^{\prime}$ was measured $7 \mathrm{~ms}$ and $5 \mathrm{~ms}$ respectively.

The response of the slow loop of the stabilizer is described by the belt delay - time $T_{\mathrm{p}}=185 \mathrm{~ms}$ and by the time constant of the regulated belt charging supply $T_{1}=140 \mathrm{~ms}$.

The other time constants are negligible as compared with the mentioned above. With practically sufficient approximation, the elements of the regulating system can be considered as linear. Linear systems are most easily handled by the use of Laplace transforms. We can write the Laplace transform of the regulator according to the block diagram in figure 2:

$$
K(p)=\frac{A}{1+p T_{\mathrm{e}}}\left[B \frac{\mathrm{e}^{-p T_{\mathrm{t}}}}{1+p T_{\mathrm{t}}^{\prime}}+C \frac{e^{-p T_{\mathrm{p}}}}{1+p T_{1}}\right]
$$

where: $A, B, C$ are the zero frequency open loop gains of the chains.

The time constant $T_{\mathrm{t}}^{\prime}=5 \mathrm{~ms}$ is small with comparison to the time constant $T_{\mathrm{e}}=0.67 \mathrm{~s}$. Therefore the transfer function of the system will be given by the formula:

$$
K(p)=\frac{A}{1+p T_{\mathrm{e}}}\left[B \mathrm{e}^{-p T_{\mathrm{t}}}+C \frac{\mathrm{e}^{-p T_{\mathrm{p}}}}{1+p T_{1}}\right]
$$

We have applied this formula to the analysis of the stability of the feedback system. The Laplace transform is simply related to the Fourier transform by a change of variable. The Fourier transform of the regulator is given by the formula:

$$
K(j \omega)=\frac{A \cdot B \cdot \mathrm{e}^{-j \omega T_{\mathrm{t}}}}{1+j \omega T_{\mathrm{e}}}+\frac{A \cdot C \cdot \mathrm{e}^{-j \omega T_{\mathrm{p}}}}{\left(1+j \omega T_{\mathrm{e}}\right)\left(1+j \omega T_{\imath}\right)}
$$

The real component of this transform is given by the expression :

$$
\operatorname{Re}[K(j \omega)]=\frac{D}{\sqrt{1+\omega^{2} T_{\mathrm{e}}^{2}}}\left\{\operatorname{Re}_{1}[K(j \omega)]+k \cdot \operatorname{Re}_{2}[K(j \omega)]\right\}
$$

and the imaginary component by the expression :

$$
\operatorname{Im}[K(j \omega)]=\frac{-D}{\sqrt{1+\omega^{2} T_{\mathrm{e}}^{2}}}\left\{\operatorname{Im}_{1}[K(j \omega)]+k \cdot \operatorname{Im}_{2}[K(j \omega)]\right\}
$$

where :

$$
\begin{gathered}
D=A \cdot B \\
k=\frac{A \cdot C}{A \cdot B}=\frac{C}{B}
\end{gathered}
$$

$\operatorname{Re}_{1}[K(j \omega)]=\cos \left(\operatorname{arctg} \omega T_{\mathrm{e}}+\omega T_{\mathrm{t}}\right)$

$\operatorname{Re}_{2}[K(j \omega)]=\frac{\cos \left(\operatorname{arctg} \omega T_{\mathrm{e}}+\operatorname{arctg} \omega T_{1}+\omega T_{\mathrm{p}}\right)}{\sqrt{1+\omega^{2} T_{1}^{2}}}$

$$
\begin{aligned}
& \operatorname{Im}_{1}[K(j \omega)]=\sin \left(\operatorname{arctg} \omega T_{\mathrm{e}}+\omega T_{\mathrm{t}}\right) \\
& \operatorname{Im}_{2}[K(j \omega)]=\frac{\sin \left(\operatorname{arctg} \omega T_{\mathrm{e}}+\operatorname{arctg} \omega T_{1}+\omega T_{\mathrm{p}}\right)}{\sqrt{1+\omega^{2} T_{1}^{2}}}
\end{aligned}
$$

where:

$D$ : the gain factor of the fast loop,

$k$ : the fast loop gain to the slow loop gain ratio.

In order to determine the admissible gain factor $D$ and the admissible gain ratio $k$ providing the stable 
operating conditions we have applied the Nyquist criterion.

At first we have solved numerically the equation:

$\operatorname{Im}[K(j \omega)]=0$

The lowest non - zero solution of the equation (8) is the critical frequency $\omega_{\text {crit }}$. If the inequality :

$\operatorname{Re}\left[K\left(j \omega_{\text {crit }}\right)\right]>-1$

holds for critical frequency $\omega_{\text {crit }}$, the feedback system is stable. The calculation was made for minimum and maximum value of load currents. The results of the calculations are presented in tables.

\section{TABLE I}

The conditions of the stable work for the two loop stabilizer

\begin{tabular}{|c|c|c|c|}
\hline & $k$ & $f_{\text {crit }}(\mathrm{cps})$ & $D$ \\
\hline$T_{\mathrm{e}}=6.35 \mathrm{~s}$ & $\overline{1.82}$ & $\overline{1.65}$ & $<\overline{31.4}$ \\
\hline minimum load & 1.6 & 36.8 & $<1440$ \\
\hline$T_{\mathrm{e}}=0.67 \mathrm{~s}$ & 1.89 & 1.74 & $<35$ \\
\hline maximum load & 1.6 & 36 & $<150$ \\
\hline
\end{tabular}

For the time constant $T_{\mathrm{e}}=6.35 \mathrm{~s}$ (minimum load) and for gain ratio $k=1.82$, the critical frequency is only $1.65 \mathrm{cps}$ and the admissible gain factor of the fast loop is less than 31.4. In order to increase the critical frequency, the gain ratio should be decreased. For $k=1.6$ the critical frequency is equal $36.8 \mathrm{cps}$ and the fast loop gain ratio should be less than 1440 . For the accelerator running with the maximum load $T_{\mathrm{e}}$ is equal $0.67 \mathrm{~s}$. Then the gain ratio is 1.89 , the critical frequency is only $1.74 \mathrm{cps}$ and the admissible fast loop gain factor is less than 35 .

For the gain ratio equal 1.6 the critical frequency is $36 \mathrm{cps}$ and the maximum gain factor of the fast loop is less then 150 . The above results are in good agreement with the experiment. We have chosen the maximum gain ratio equal 1.6 and the maximum fast loop gain factor equal 100 , that is compatible with a stable system in the whole range of load currents.

TABLE II

The conditions of the stable work for the one loop stabilizer with the corona-triode.

$\begin{array}{lcc} & f_{\text {crit }}(\mathrm{cps}) & \bar{D} \\ \begin{array}{l}T_{\mathrm{e}}=6.35 \mathrm{~s} \\ \text { minimum load }\end{array} & 35.7 & <1420 \\ \begin{array}{l}T_{\mathrm{e}}=0.67 \mathrm{~s} \\ \text { maximum load }\end{array} & 35.9 & <150\end{array}$

There is a possibility of working with the coronatriode alone (table II). The bandwidth and the gain is then comparable with those discussed above, but the range of stabilization is smaller. The range of two loop stabilizer is approximately $200 \mathrm{kV}$, while the range of corona - triode stabilizer is at most $50 \mathrm{kV}$.

TABLE III

The conditions of the stable work for the one loop stabilizer with the regulation of the belt charging current.

$\begin{array}{lcc}T_{\mathrm{e}}=6.35 \mathrm{~s} & \overline{-} & <41 \\ \text { minimum load } & 0.83 & \\ \begin{array}{l}T_{\mathrm{e}}=0.67 \mathrm{~s} \\ \text { maximum load }\end{array} & 0.96 & <5.45 \\ \text { maximu } & & \end{array}$

The work with the slow loop alone (table III) is impossible because the bandwidth and the permissible gain are then far too small $\left(f_{c r i l}=0.83-0.96 \mathrm{cps}\right.$, the gain less than 5.45). 